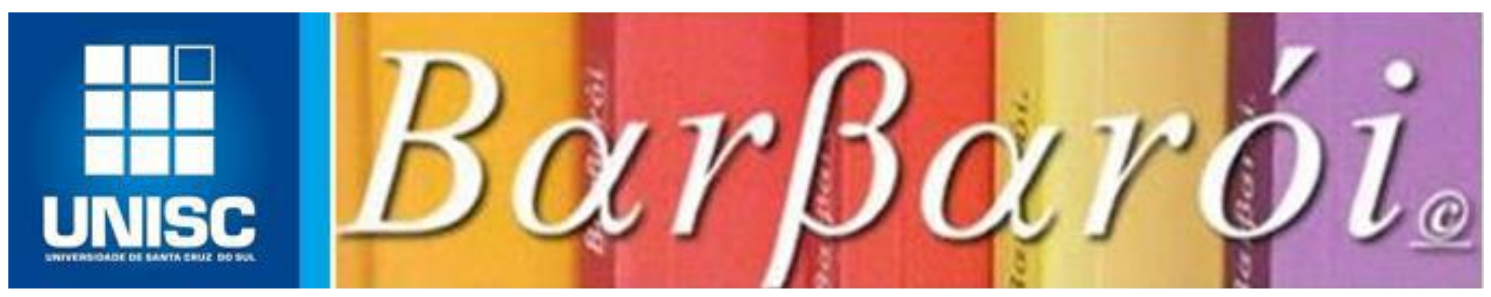

\title{
REDUÇÃO DE DANOS E GESTÃ̃ AUTÔNOMA DA MEDICAÇÃO: CARTOGRAFANDO A EXPERIÊNCIA DE UM ACADÊMICO EM PSICOLOGIA
}

\author{
DOI: http://dx.doi.org/10.17058/barbaroi.v0i0.14070 \\ $*$
}

\author{
Thales William Borges Lindenmeyer \\ Universidade Federal de Santa Maria - UFSM - Brasil \\ Maria Luiza Diello \\ Universidade Federal de Santa Maria - UFSM - Brasil
}

Marcos Adegas de Azambuja

Universidade Federal de Santa Maria - UFSM - Brasil

\begin{abstract}
$*$
\section{Resumo}

Este artigo tem como objetivo cartografar a experiência de um acadêmico de Psicologia em um encontro na cidade de Santa Maria/RS, com a temática de Redução de Danos (RD) e Gestão Autônoma da Medicação (GAM). Na ocasião estavam presentes usuários, estudantes, residentes, professores e profissionais do campo da saúde mental, álcool e outras drogas. O gatilho para o pesquisar foi a afetação do estudante a partir da fala de uma profissional que disse: "eu prefiro um usuário de crack internado, amarrado e babando numa maca de hospital do que oferecendo perigo para a sociedade. Nunca vi um usuário de medicamento matar para sustentar o vício". Um usuário, por sua vez, a respondeu: "a senhora nunca viu um usuário de medicamentos matar para sustentar o vício porque a droga dele tem em qualquer farmácia". Inspirados pela cartografia, efetuamos um olhar para as reverberações desse acontecimento, constituindo nossa trajetória/método. Buscamos construir uma narrativa histórica das drogas por meio do campo discursivo da RD e GAM, além de mapear a produção de subjetividade na relação com as drogas nos movimentos desse encontro. Consideramos, por fim, que há algo de novo entre RD e GAM: o uso de medicamentos vem se tornando um problema tão importante quanto o consumo de drogas ilícitas. São investidos saberes e práticas para dar conta de inventar e disputar formas de entender e conduzir os modos de vida que incluem as substâncias psicoativas.
\end{abstract}

Palavras-chave: redução de danos; gestão autônoma da medicação; cartografia. 


\section{Introdução}

Uma agente comunitária comentou: "acho que precisamos pensar sobre os medicamentos. Concordo com o que foi dito na palestra hoje de manhã. Um benzodiazepínico pode ser tão perigoso quanto o crack". Pensei, feliz, que alguma coisa acontecia na roda de conversa. Arriscávamos com maior ousadia partilhar percepções. De repente alguém irrompe em sua cadeira: "Muito ingênua a tua fala. Eu prefiro um usuário de crack internado, amarrado e babando numa maca de hospital do que oferecendo perigo para a sociedade. Nunca vi um usuário de medicamento matar para sustentar o vício”. Era uma psiquiatra. Com as bochechas incendiadas pelo afeto que me atravessava, respondi ironicamente: "Mas quem sabe a gente mata o usuário de uma vez, se o objetivo é não oferecer perigo? Morto não oferece perigo". Em seguida alguém no outro extremo da roda rebate: “A senhora nunca viu um usuário de medicamentos matar para sustentar o vício porque a droga dele tem em qualquer farmácia". A médica não respondeu o usuário. Aos poucos o ambiente de conflito foi se dissolvendo, outros temas e velocidades ganharam corpo. No intervalo a psiquiatra perguntou quando seriam emitidos os certificados. E foi embora.

Este artigo tem como objetivo cartografar a experiência de um acadêmico de Psicologia em um encontro na cidade de Santa Maria/RS com a temática de Redução de Danos (RD) e Gestão Autônoma da Medicação (GAM). Busca construir uma narrativa histórica das drogas por meio do campo discursivo da RD e GAM, além de mapear a produção de subjetividade na relação com as drogas nos movimentos desse acontecimento.

A atividade fez parte da articulação de dois programas de extensão ${ }^{i}$ na Universidade Federal de Santa Maria. As ações objetivavam oferecer suporte teórico-prático para a abertura e manutenção de grupos GAM, e incluíram visitas nos serviços da região, bem como o oferecimento de uma qualificação. Esta última ocorreu na UFSM no segundo semestre de 2017. Foram seis encontros presenciais de frequência mensal. As atividades eram divididas em dois momentos: pela manhã uma palestra de temática relacionada a GAM e no período da tarde rodas de conversa para compartilhar percepções. Uma dessas rodas tinha como tema a questão das drogas e a perspectiva da RD. Foi nessa ocasião que agente comunitária, médica, acadêmico e usuário produziram a discussão que é cena desse relato de experiência.

As origens da RD remontam ações que ocorrem desde 1926 na Europa, com o objetivo de prevenção e redução de índices epidêmicos de hepatite e HIV/AIDS. Profissionais de saúde distribuíram seringas para usuários de heroína entendendo que uma das principais causas da transmissão era o compartilhamento dos instrumentos utilizados para o consumo (DOMANICO, 2006). No Brasil, a RD se instalou com ampla adesão nas comunidades, Barbarói, Santa Cruz do Sul, n.54, p.<119-136>, jul./dez. 2019 
reduzindo a taxa de incidência de DSTs e HIV entre usuários de drogas injetáveis de 25\% para 13\% (TEDESCO; SOUZA, 2009). Em 2010 os princípios da RD foram incluídos como objetivos da Rede de Atenção Psicossocial, postulando que as intervenções de saúde dirigidas aos usuários abusivos de álcool e outras drogas devem ser ampliadas e estar baseadas na melhoria da qualidade de vida das pessoas (BRASIL, 2011). Em uma migração gradual do campo das doenças sexualmente transmissíveis para o das drogas ilícitas, as práticas da RD estão baseadas na informação, educação, assistência social e saúde, além da diminuição de danos causados por diversos fatores que compõem, junto com as drogas, uma complexa paisagem na vida dos usuários. Tal política tem efeito direto nos modos de fazer e pensar a clínica, orientando-se em transformar investimentos mortíferos que se imprimem em maus encontros com as drogas a partir da atenção e intervenção no processo de produção de uma subjetividade-drogadita (TEDESCO; SOUZA, 2009).

A GAM, por sua vez, é um dispositivo criado por usuários de psicofármacos do Canadá (CAMPOS et al, 2012). Motivados pela percepção de que estavam hipermedicalizados, os usuários almejavam reduzir ou acabar com o consumo de psicofármacos. Entendendo que a sobreposição do saber médico-profissional ao poder de decisão dos usuários era assimétrica, eles produziram o guia que é utilizado como instrumento de manejo de um grupo. Nele se constroem processos de protagonismo e corresponsabilização, norteados pela autonomia e cogestão dos participantes com relação à escolha de seu próprio tratamento em saúde mental, além de tocar também em outros temas relacionados à vida e cidadania (CAMPOS et al, 2012). Trata-se de um conceito de autonomia que se refere a pluralidade de vínculos que se é capaz de estabelecer: quantos mais vínculos e redes de relações uma pessoa constrói, mais autônoma ela se torna (CAMPOS et al, 2012).

A GAM surge no Brasil por intermédio das universidades. A "Pesquisa avaliativa de saúde mental: instrumentos para a qualificação da utilização de psicofármacos e formação de recursos humanos - GAM-BR" ocorreu entre 2009 e 2011 envolvendo os estados do Rio de Janeiro, São Paulo e Rio Grande do Sul. Nesse último foi criada em 2015 a pesquisa "Implementação e descentralização da estratégia da Gestão Autônoma da Medicação (GAM) no estado do RS: efeitos de disseminação". Trata-se de um projeto multicêntrico atendendo as regiões metropolitana, sul e centro-oeste do estado. Chegamos, portanto, em Santa Maria/RS, onde há combinação de projetos de pesquisa e programas de extensão que atuam na disseminação e consolidação da estratégia GAM.

Este relato pretende reconstituir o vivido em experiência. Lida, portanto, com processos que não dizem respeito somente a cena evocada, mas também a escrita e reescrita de Barbarói, Santa Cruz do Sul, n.54, p.<119-136>,jul./dez. 2019 
sensibilidades e percepções. Para tanto, temos em mente algumas considerações sobre o que é experiência. "Configurada como um acontecimento real, localizado em tempo real e com pessoas reais, a experiência subjetiva abarca domínios que ultrapassam o nível verbal, consciente, representável e mesmo psicológico, dos domínios de um ego. Experiência dos afetos, singular e intransmissível, que não é redutível aos atos programados pela inteligência e pelo savoir-faire" (FONSECA et al, 2018, p. 180).

Inspirados por considerações sobre cartografia (PASSOS; KASTRUP; ESCÓSSIA, 2012), deslizamos por instantes de fuga de uma pesquisa que apenas descreve e representa o objeto investigado. Nosso objeto é a experiência e o conhecimento, não os atores que agenciaram o encontro. Esses todos se transformam em sujeitos em uma visão sobre a realidade entendida como produto de modos de ver e de dizer criados num determinado momento histórico (FOUCAULT, 1979). Sujeito, objeto e experiência se constituem no próprio trajeto percorrido brincando com a definição de método "como um caminho (hódos) predeterminado pelas metas dadas de partida. [...] a cartografia propõe uma reversão metodológica: transformar o metá-hódos em hódos-metá” (PASSOS; KASTRUP; ESCÓSSIA, 2012, p. 10). Assim, tratamos de práticas discursivas e não discursivas enquanto agenciamentos sobre o que podemos dizer sobre mundo e que ações mudas dos corpos criam modalidades de ver (PASSOS; KASTRUP; ESCÓSSIA, 2012). Algo pôde ser dito sobre drogas e usuários na cena evocada no início desse texto. Estamos atentos a seguinte pergunta: quais seriam as forças que atravessaram o grupo e concretizaram a luta de saberes sobre os sujeitos e as drogas?

\section{O percurso para a cartografia da experiência}

A inquietação produzida no conflito da cena supracitada nos mobilizou em direção a uma estratégia que desse conta de trazer o embate entre os diferentes modos de dizer e fazer sobre o problema drogas, incluindo também a experiência do acadêmico como algo a ser analisado. Essa luta não é tomada como constituinte dos bastidores do saber, mas justamente como aquilo que o configura, em uma perspectiva que entende a produção de conhecimento simultânea a construção de sujeitos e objetos em processos contextualizados e historicizados (BERNARDES; SCISLESKI; PELLICCIOLI, 2016).

Encontramos inspiração no método da cartografia (BARROS; KASTRUP, 2012) para mapear a produção de subjetividade na relação com as drogas nos movimentos desse encontro. A subjetividade é produzida por agenciamentos de enunciação. Acompanhando Deleuze (1997), "todo agenciamento é, em primeiro lugar, territorial. O território cria o agenciamento. O território excede ao mesmo tempo o organismo, o meio, e a relação entre ambos" (p. 218). 
Propomos pensar o agenciamento como algo em que pode-se distinguir o que se faz e o que se diz, o conteúdo e a expressão. O sujeito que se desprende a cartografar desenha uma rede de forças sobre o fenômeno em questão que provocou a inquietação motivadora do ato da investigação (BARROS; KASTRUP, 2012). Trata-se, portanto, de um campo epistemológico em que se pensa com o plano das formas (correspondente as figuras já estabilizadas) e com o plano movente das forças que produzem as formas em coagulações e conglomerados de vetores (ESCÓSSIA; TEDESCO, 2009), também chamados de afetos. Tais forças são, a saber, práticas, sendo elas discursivas e não discursivas. Lidamos, portanto, com a estabilidade das posições agente comunitária de saúde, médica, acadêmico e usuário, bem como o que é dito e feito a partir das práticas possíveis nesses territórios. Simultaneamente, levamos em consideração os interstícios, as misturas que são atravessadas desde a disparidade de trajetórias de vida e cosmovisões até a configuração das classes em uma sala de aula de uma universidade. Esses e outros elementos produzem, coletivamente, subjetividades.

Entendemos que o que dizemos não é somente nosso (DELEUZE, 1992), e o que movimenta a escrita é a experiência do acadêmico que explora caminhos e questões. Em alguns momentos no território da militância antimanicomial, esse acadêmico estava no quarto semestre de um curso de Psicologia e residia em uma casa do estudante ${ }^{i i}$. Utilizou-se dos registros de seu caderno de campo e da montagem de uma narrativa sobre a cena supracitada a partir de conversas com outros participantes do encontro para reconstituir o vivido em experiência. Outro registro material das coisas pensadas, lidas e ouvidas foi a própria processualidade desse escrito, nos fazendo pensar sobre um simulacro de hypomnemata (FOUCAULT, 2009) que foi possível a partir das errâncias e inquietações diante da seguinte questão: o que é (ou está sendo) cartografar uma experiência?

\section{A Redução de Danos e seus trajetos}

Como sabemos, o consumo de substâncias psicoativas é um elemento que compõem a história da humanidade em diferentes nuances, dependendo da localidade e temporalidade na qual analisamos. Cerimônias e rituais, prazer e emoção, experiências místicas, são formas de produzir sentido ao consumo do que chamamos de droga, hoje, em diferentes culturas. Encontramos as chamadas drogas desde a antiga Grécia, com o uso do ópio para alívio da dor e tranquilizante, assim como com os egípcios, que usavam o vinho e a cerveja para tratamento de doenças, passando pelos indígenas, com bebidas fermentadas para rituais e celebrações, até as cerimônias católicas, protestantes, judaicas, afro-brasileiras. As drogas suscitam uma infinidade de maneiras pelas quais estabelecemos relações com outras pessoas, com os meios Barbarói, Santa Cruz do Sul, n.54, p.<119-136>, jul./dez. 2019 
sociais que circulamos, com a forma que entendemos a nós mesmos e aos outros (CARNEIRO, 2014). Cana de açúcar, tabaco, cachaça e café constituíram-se no Brasil como as mais importantes drogas no âmbito cultural e econômico (CARNEIRO, 2014).

A "Lei Seca", desenvolvida entre as décadas de 1920 e 1930, e a "Guerra contra as drogas", no governo de Nixon em 1970, são pistas para pensar o que marca a diferença entre o café e a maconha. A classificação entre drogas lícitas e ilícitas, as primeiras de comercialização regulamentada e portadora de aceitabilidade social, e as segundas consideradas proibidas e associadas a criminalidade (MACHADO; BOARINI, 2013) é o pano de fundo para a materialização da política antidrogas no Brasil (BRASIL, 1976). Nesse contexto, no intuito de prevenir e repreender o tráfico ilícito e o uso de entorpecentes pela população, a política antidrogas tornou a abstinência e a intolerância ao consumo como condições de acesso aos programas de tratamento ao uso abusivo (PASSOS; SOUZA, 2011).

Com o objetivo de oferecer outros repertórios e produzir melhores índices em saúde que as primeiras ações em RD foram executadas no Brasil. Tais estratégias foram inspiradas em diversos marcos históricos, como a prescrição controlada de morfina e heroína em 1926 na Inglaterra e a elaboração de programas para redução da disseminação de doenças por usuários de drogas injetáveis na Holanda em 1972 (DOMANICO, 2006). O palco das primeiras experimentações da RD em solo brasileiro foi Santos, em São Paulo (PASSOS; SOUZA, 2011). Assim como na experiência holandesa, foram distribuídas seringas para diminuir índices de HIV entre a população que consumia drogas injetáveis (TEDESCO; SOUZA, 2009). A partir da criação do primeiro projeto de redução de danos no Brasil, em 1993, a ideia foi se espalhado por outros estados (TEDESCO; SOUZA, 2009), somando-se aos movimentos sociais em ascensão.

Na década de 1980 houve a efervescência de diversos movimentos sociais pela garantia de direitos e democracia. Nessa esteira de deslocamentos, as reformas sanitarista e psiquiátrica endossaram o que se tornou o campo fértil para o nascimento do Sistema Único de Saúde (SUS). A Saúde Mental passou a ser pensada a partir da humanização dos serviços no cuidado do usuário. No âmbito da saúde pública, a Política de Redução de Danos foi inserida institucionalmente no SUS em 1994 (PACHECO, 2013), e tem em suas diretrizes o respeito à liberdade de escolha do usuário em sua relação com as drogas e o direito à integralidade da assistência e cuidado pelos serviços sociais e de saúde (FLACH, 2010). Após a ampliação do tema das doenças sexualmente transmissíveis para a redução de danos sociais e à saúde (BRASIL, 2005), a RD, na década de 2010, foi inclusa como um dos objetivos da Rede de Atenção Psicossocial, entendida como um conjunto de serviços de saúde direcionados ao Barbarói, Santa Cruz do Sul, n.54, p.<119-136>, jul./dez. 2019 
atendimento de pessoas com sofrimento ou transtorno mental e com necessidades decorrentes do uso abusivo do álcool e outras drogas (BRASIL, 2011).

Encarar a droga como apenas um elemento de um "contexto geral sobre o qual a prática de saúde incide" (TEDESCO; SOUZA, 2009, p. 142) e garantir a liberdade e protagonismo do usuário em seu tratamento podem ser lidos como estratégias e desafios no plano comum entre RD e GAM.

\section{Pensando as drogas com a GAM}

O guia GAM foi inventando por usuários canadenses. Eles tinham como objetivo construir uma ferramenta de cuidado em saúde mental para além do uso de medicamentos psicotrópicos. Era "um contexto onde a forma de usar medicamentos nos tratamentos em saúde mental era pouco ou nada criticada" (CAMPOS et al, 2014, p. 12). Sua produção foi coletiva, e envolveu a constatação de que "mesmo que muitos usuários admitissem que os medicamentos ajudavam a reduzir o sofrimento, com frequência eram precisas longas peregrinações até conseguir informações básicas sobre o seu tratamento e a prescrição de doses mais adequadas a cada caso particular" (CAMPOS et al, 2014, p. 12). Voltada às pessoas com transtornos mentais graves, a GAM valoriza e entende como legitima as falas, demandas e a experiência singular dos usuários com as medicações, e que esse encontro produz um saber que precisa ser levado em conta no momento da prescrição e da gestão do tratamento em sua integralidade (CAMPOS et al, 2012).

Os movimentos da luta antimanicomial e da desinstitucionalização (AMARANTE, 2000; BASAGLIA, 1985) tomaram proporções internacionais, reverberando intensamente no contexto brasileiro e dando corpo para uma Reforma Psiquiátrica. Os novos ares da redemocratização, concretizados na Constituição de 1988, suscitaram diversas questões sobre a gestão do Estado. Orientado por uma certa noção de cidadania, o SUS surge como um sistema construído com base em princípios políticos de solidariedade social, asseguração da participação da população, universalidade ao acesso em saúde, equidade e integralidade da atenção. A Saúde Mental é, assim, tensionada dentro e fora do campo institucional, posta em movimento para a construção de sujeitos cidadãos de direito (BRASIL, 2001), acolhendo a diferença, e esbarrando em limites materiais, como a lenta transição do modelo hospitalocêntrico para um modelo de saúde mental comunitária. Ampliou, contudo, o campo da clínica, qualificando a atenção como psicossocial, redefinindo o sentido de saúde na fronteira entre o individual e o coletivo. 
Um desafio sinalizado pelos usuários canadenses persiste por aqui: o tratamento farmacológico aparece amplamente privilegiado para enfrentar os problemas de saúde mental. A qualificação da utilização de psicofármacos e a qualificação de pessoal têm sido pontos sensíveis da expansão da rede (FIGUEIREDO; CAMPOS, 2008). Sensibilidade esta que desemboca na problematização sobre a existência de uma camisa de força química. Verifica-se muitas vezes que o tratamento em saúde mental está reduzido aos psicotrópicos e que a comunicação entre os profissionais de saúde e usuários sobre o tratamento é precária (SANTOS, 2009). Um estudo aponta o crescimento do uso de psicofármacos mais elevado do que o preconizado pela literatura, tanto em quantidade quanto em duração (HULL, 2005). A prevalência dessas medicações é associada a vulnerabilidade social, baixa escolaridade e menor renda per capita (ROBERTS, 1998). O fenômeno da medicalização, entendido como a transformação de situações corriqueiras em objeto de tratamento da medicina, portanto, mostrase associado a fatores socioeconômicos (MARAGNO, 2006), assim como a questão das drogas ilícitas.

A GAM e a RD surgem como uma certa continuidade e complementaridade dos movimentos da Reforma Psiquiátrica. A primeira proposta trabalha com os princípios da autonomia e cogestão, considerando os usuários protagonistas de seus tratamentos que se efetivam na relação e partilha com os outros, ampliando coletivamente as possibilidades de cuidado (CAMPOS et al, 2014). A segunda, por sua vez, perturba a subjetivação-drogadita, ampliando a atenção clínica mais para um mapa existencial do que para o consumo de determinada substância (TEDESCO; SOUZA, 2009). Tal similaridade constituída pela intersecção entre as duas propostas nos convoca a pensar sobre que modos de existência são possíveis quando a droga ilícita e a psicofarmacológica se tornam um problema público e comum.

\section{Um mapa da experiência do acadêmico}

O dia, já não lembro, se era ensolarado ou nublado. A vida era intensa. Prédio limpo, terceiro andar, cadeiras e mesas dispostas em círculo na sala de aula. Estávamos entre trinta pessoas. Muitas delas chegaram de viagem de alguns municípios da região centro-oeste do Rio Grande do Sul. Em sua maioria, residentes e profissionais. Havia um número considerável de usuários. Alguns estagiários também estavam presentes, além de professores pesquisadores. Aliás, todos ali eram pesquisadores, de acordo com as propostas do encontro ${ }^{\text {iii }}$.

A roda de conversa era o segundo momento das atividades: naquela manhã, no mesmo prédio, ouvi uma palestra sobre a RD. Eram dois convidados, um professor universitário e um Barbarói, Santa Cruz do Sul, n.54, p.<119-136>, jul./dez. 2019 
redutor de danos de Santa Maria. Sobre a fala do primeiro, o que registrei foi a narrativa de sua trajetória com medicamentos, relatando que deixou de sentir afetação pelas artes na medida em que um antidepressivo agia sobre o seu corpo. Também contou sobre a problematização e redimensionamento da abordagem sobre a noção de droga, destacando uma experiência em que se viu fazendo uma pergunta boba e ingênua: o que é droga? Ele disse que muitos estudantes de farmácia se formavam sem ter uma resposta para essa questão, e que a ciência tratava de fazer muita confusão com relação ao tema. Um movimento possível frente a isso, segundo ele, seria dar um passo atrás e questionar o que parece óbvio, alguma concepção que todos deveriam saber, mas que, no fim das contas, dificilmente sabíamos se estávamos falando da mesma coisa. Ele apresentou o conceito de droga que engloba toda a substância que introduzida no organismo vivo modifica uma ou mais das suas funções normais. Apontou sobre a imprecisão do termo, na medida em que qualquer substância pode modificar as funções normais de um organismo e que inclusive, eventos da vida corrente podem produzir esse efeito. O próprio termo "função normal" levanta suspeita: que função é essa e quais são os procedimentos necessários para que ela se efetue? Terminou apontando que é preciso sair do campo discursivo 'emburrecedor' sobre as drogas e produzir problematizações e pensamento, para que se possa olhar também para a vida enquanto potência e intensidade.

O Redutor de Danos, por sua vez, era um jovem morador da periferia da cidade. Foi uma das primeiras pessoas a assumir o cargo de Redutor de Danos no serviço público de saúde, e segue desenvolvendo o trabalho em sua comunidade, mesmo não ocupando o cargo institucionalizado pelo município. Ele contou algumas histórias. Disse que, certa vez, uma senhora não estava frequentando o serviço de referência em saúde do seu bairro, não buscando os medicamentos necessários para o tratamento de determinada patologia de um dos membros da família. Partiu para uma visita domiciliar. Chegando lá, a senhora estava cozinhando alguma coisa na panela. Contou ele que a casa era simples: fogão feito com tijolos no chão e que um menino brincava na volta, de tempos em tempos questionando quando que a comida estaria pronta e reclamando que estava com fome. Em meio aquele cenário, o Redutor de Danos perguntava para a senhora o que estava acontecendo, quais eram os motivos de não estar frequentando a rede de saúde. Conversa vai, conversa vem, e a senhora seguia cozinhando, tapando a panela com um pedaço de papelão, como que se guardasse um segredo. O horário do almoço já estava chegando quando o Redutor indagou se poderia comer junto com eles. A senhora, ao ouvir a pergunta, desaba em choro. Em seguida mostra o que estava sendo preparado: na panela havia água, um osso sem carne e recortes de jornal de supermercado. Cebola, tomate, cenoura e carnes feitos de papel eram cozinhados, representando um alimento Barbarói, Santa Cruz do Sul, n.54, p.<119-136>,jul./dez. 2019 
verdadeiro. O redutor de danos fechou a história ressaltando que muitas vezes, questões anteriores ao problema das drogas são urgentes. Uma delas é a fome. Outra, ainda, é a violência policial, e sobre isso ele trouxe vivências. Quando a mesa abriu para perguntas, uma médica interpelou o Redutor, alegando que ele estava exagerando, porque muitos policiais eram pessoas de bem. Dei-me conta, incrédulo, de que ela não o havia escutado.

Estamos chegando na tão esperada cena que fez disparar a cartografia da experiência acadêmica. Após a palestra da manhã, fomos almoçar no restaurante universitário. Acompanhamos alguns usuários. Uma delas, antes de comer, tomou com um só punhado uma dezena de comprimidos. Assim que engolidos, seu corpo estremece. Com olhos arregalados, me perguntei se o efeito da medicação era imediato. Refeição atormentada. Fomos para a roda de conversa. Antes de entrar na sala, os professores pesquisadores conversaram conosco, bolsistas. Perguntaram como estávamos depois das provocações da médica na palestra. Eu confessei que estava mal, incomodado, e que não entendia direito quais eram os limites entre respeitar a experiência do outro e deixar de me colocar, de expor minha divergência. Um dos professores, por sua vez, me respondeu dizendo que na roda que aconteceria a seguir eu poderia me autorizar a dizer mais sobre essas inquietações, porque é isso que produz pensamento. Tomado por todos esses afetos, entrei na sala.

Uma agente comunitária quebrou a timidez e o silêncio comentando: "acho que precisamos pensar sobre os medicamentos. Concordo com o que foi dito na palestra hoje de manhã. Um benzodiazepínico pode ser tão perigoso quanto o crack”. Pensei, feliz, que alguma coisa acontecia na roda de conversa. Arriscávamos com maior ousadia partilhar percepções. De repente alguém irrompe em sua cadeira: "Muito ingênua a tua fala. Eu prefiro um usuário de crack internado, amarrado e babando numa maca de hospital do que oferecendo perigo para a sociedade. Nunca vi um usuário de medicamento matar para sustentar o vício". Era uma psiquiatra. Com as bochechas incendiadas pelo afeto que me atravessava, respondi ironicamente: "Mas quem sabe a gente mata o usuário de uma vez, se o objetivo é não oferecer perigo? Morto não oferece perigo". Em seguida alguém no outro extremo da roda rebate: "A senhora nunca viu um usuário de medicamentos matar para sustentar o vício porque a droga dele tem em qualquer farmácia”. A médica não respondeu o usuário. Aos poucos o ambiente de conflito foi se dissolvendo, outros temas e velocidades ganharam corpo. No intervalo a psiquiatra perguntou quando seriam emitidos os certificados. E foi embora.

É preciso situar historicamente a emergência do consumo de drogas como um objeto a ser investido pelos campos de saber e de poder. É somente no final do século XIX e início do século XX que o uso e abuso de drogas passa a ser visto como um problema para a sociedade Barbarói, Santa Cruz do Sul, n.54, p.<119-136>,jul./dez. 2019 
ocidental. Devido aos processos de urbanização e industrialização, a necessidade de organização da cidade, a preocupação com a distribuição e com a utilidade da população em seus espaços e tempos de vida para a economia e produção do Estado, o olhar sobre aqueles que perdiam sua funcionalidade é alterado. Surge a necessidade de intervenção. Assim, a vida do louco, do ocioso, do desempregado, do criminoso e, junto a essas categorias, do drogado e do delinquente, torna-se objeto das disciplinas de conhecimento e do poder público (FOUCAULT, 1983).

A medicina é um dos campos de saber que se dissemina nessa época, articulando-se ao aparelho de Estado para administrar a vida ou a saúde populacional. A preocupação com o bemestar justifica a delimitação e restrição de determinados grupos e indivíduos tidos como inadequados em diversas posições nas instituições, tais como família, escola e trabalho, e o concomitante uso de substâncias ilícitas no quadro composto por esse sujeito desviante. A transexual expulsa de casa, o garoto agitado na sala de aula e a trabalhadora que prefere ficar em casa a desossar frangos na indústria. Esses elementos podem compor um chamado "grupo de risco", articulando, assim, ao mesmo tempo uma descrição das características de probabilidade de incidência de danos aos indivíduos e grupos, bem como uma série de práticas e procedimentos para o trato com essa situação.

Quanto à minha experiência de acadêmico em Psicologia, volta e meia o tema das drogas era tocado em sala de aula. Meio de canto, pairando aqui e ali, mas quase sempre quando o assunto era trazido por estudantes. Em uma dessas vezes, estávamos eu e uma amiga/mestranda/colega/pesquisadora; o objetivo da aula era contar um pouco sobre os grupos de pesquisa que existiam no curso. Para tanto, era inevitável falar sobre a GAM e a RD. A conversa foi andando e se aproximando do tema da diferença entre um usuário de medicamento e de droga ilícita. Eu e a pesquisadora sustentamos que era possível perceber semelhanças entre um médico e um traficante, na medida em que muitas receitas eram distribuídas na base da tentativa-erro e que os danos provocados pelos tratamentos variam bastante, chegando, em alguns casos até mesmo à morte tanto no uso de lícitos, quanto de ilícitos. Destacamos, também, que a questão principal não precisa ser fundamentalmente o uso de drogas lícitas e ilícitas, mas também os diferentes usos e abusos que se faz não somente de drogas, mas de qualquer substância, situação ou afeto/afetação; além do que, é preciso considerar que nem todo uso é abusivo ou problemático. O medicamento químico, a droga lícita, pode ser utilizado como suporte para o manejo do organismo, em situações necessárias, e isso não tem que se tornar crônico ou problemático. A droga ilícita também, sendo utilizada por muitas pessoas com 
finalidade recreativa ou como suporte terapêutico para o manejo de algum estado físico ou psicológico.

Vejamos que um estudo feito nos Estados Unidos, por exemplo, sinaliza que a terceira maior causa de morte são erros médicos (MAKARY, 2016). Levando em conta que uma das funções médicas é a prescrição de medicamentos, tais apontamentos são um convite para pensarmos o problema da medicação. No contexto do Brasil, em Campinas, no primeiro semestre de 2010, apenas na rede pública de farmácias, 65.758 pessoas receberam prescrição de psicofármacos, o que equivale a 6,5\% da população (SANTOS, 2009). Esses e tantos outros estudos nos permitem pensar sobre a medicalização, conceituado enquanto o fenômeno de transformação de situações corriqueiras em objeto de tratamento da medicina.

O professor, por sua vez, nessa cena entre eu e a amiga mestranda, rebateu enfatizando que as coisas eram muito diferentes. Disse que usuários de crack, por exemplo, só viviam para sustentar o seu vício. Contou que já havia passado de carro pelo entorno da rodoviária de Porto Alegre/RS e que testemunhou isso: as pessoas eram zumbis e só queriam usar sua droga. Questionamos se o professor havia descido do carro e conversado com aquelas pessoas, se aproximado daquele território. A resposta, como esperado, foi negativa. Saí da sala com uma coisa em mente: que através de um para-brisa de carro, qualquer um pode ter sua vida resumida a um consumo e, consequentemente, ser dado como zumbi.

A primeira vez que tive contato com um usuário de saúde mental foi em casa, interagindo com membros da família. A princípio não havia algo que constituía uma diferença entre eu e um parente que frequentava um Centro de Atenção Psicossocial ou fazia uso de um chamado "tarja preta". Foi só na universidade que um véu de mistério foi sendo construído com relação a essas pessoas, atribuindo um significado que eu não costumava associar. Considerando essa nova etiqueta que a formação acadêmica me proporcionou, tive o primeiro contato com uma usuária de saúde mental em um dos encontros multicêntricos da GAM na região centro oeste. Conversei com uma mulher que, em poucos instantes, contou um extenso percurso de vida, com experiências fortes e que usualmente não são ditas em qualquer contexto. Mais tarde, depois do término da reunião, uma das pesquisadoras relatou ser comum esse fenômeno, na medida em que os usuários são incentivados a falar sobre suas vidas constantemente, atendendo uma necessidade delineada pelo grande fluxo de profissionais dentro dos serviços de Saúde Mental. Uma diferença no âmbito da fala, portanto, foi a que marcou esse primeiro contato.

Voltando ao episódio envolvendo a médica presente na roda de conversa, em que um usuário respondeu à mesma, contrariando suas ideias, o tema da fala também emergiu. Muitos Barbarói, Santa Cruz do Sul, n.54, p.<119-136>, jul./dez. 2019 
dos pesquisadores ali presentes partilhavam ideias semelhatnes com relação à violência e drogas proibidas, mas somente a agente comunitária, alguém que não havia passado por uma graduação, ousou desafiar a autoridade médica presente. Na roda havia inclusive residentes Redutores de Danos com extensa leitura e escrita sobre o assunto. Tal acontecimento me suscitou algumas questões com relação ao conhecimento acadêmico e o que se faz com ele. $\mathrm{O}$ campo do saber ali manifesto parecia ser subordinado ao do discurso médico, isto é, o que antes falávamos sobre a identificação de anormais e sobre as práticas e procedimentos para lidar com estas pessoas. Mesmo quando um conhecimento era produzido de forma a constituir uma resistência pela via da Psicologia e dos movimentos de luta antimanicomial, a esteira em que os pensamentos estavam andando era a mesma que legitimava a fala da médica. Produzir para o quê? De que valia leituras intermináveis de Deleuze, Guattari, Foucault e tantos outros, se perante um discurso fascista (FOUCAULT, 2009) o que resta é o silêncio? A potência de ter alguém minimamente distanciado desse círculo acadêmico me pareceu saltar aos olhos. E se não houvesse usuários na reunião, ocupando as universidades e espaços de produção de pensamento formais, quem questionaria um procedimento de morte frente ao risco?

\section{Considerações}

Há algo de novo no encontro entre RD e GAM: novas formações subjetivas singulares são produzidas, novas falas emergem e são ouvidas, outros silêncios são inventados. A RD, já consolidada como política pública, parece disseminar-se com facilidade por entre serviços e universidades na $4^{\mathrm{a}} \mathrm{CRS} / \mathrm{RS}$. Desterritorializações e reterritorializações acontecem na medida em que os sedimentos do terreno acadêmico se movem.

Vivemos em um contexto em que, no momento da prescrição, os profissionais de saúde não consideram o que os usuários tem a dizer sobre os medicamentos que usam ou usaram, e que a participação das pessoas em seus tratamentos, desinformadas sobre seus direitos, está restrita a descrever o seu mal-estar (CAMPOS et al, 2014). Produzimos uma gestão independente do medicamento e da droga, e essa autossuficiência nem sempre leva ao melhor resultado ou situação, como quando um usuário decide interromper seu tratamento sem comunicar suas redes. O mesmo pode acontecer com a situação das drogas ilícitas, na medida em que profissional e usuário se iludem mutualmente com as ideias de que irão, respectivamente, salvar alguém em sofrimento e seguir fielmente a abstinência, em uma concepção de intervenção que não é coletiva.

Podemos destacar que o uso de medicamentos vem se tornando um problema tão importante quanto o consumo de drogas ilícitas. RD e GAM, através da valorização da Barbarói, Santa Cruz do Sul, n.54, p.<119-136>, jul./dez. 2019 
cogestão, autonomia e direito dos usuários, vêm apresentando um novo repertório para movimentar pensamentos e práticas. Os desafios da Reforma Psiquiátrica, antes marcados pela urgência da revisão do modelo hospitalocêntrico de cuidado, atualizam-se também no âmbito dos serviços substitutivos e Atenção Básica em um tema que atravessa nosso tempo: a naturalização do tratamento medicamentoso para qualquer mal-estar humano. Novas fronteiras são desenhadas na discussão sobre democracia e governo dos corpos quando questionamos a desconsideração de saberes diferentes do produzido pelo discurso médico ocidental.

Com relação a experiência acadêmica, foi inevitável tomar partido pelo lado do usuário e criar um espectro vilanesco na figura da médica, assim como do professor que, por trás do vidro, vê e emite juízos de valor e de pouco conhecimento sobre a vida como ela é. Mesmo tendo em vista que os discursos ultrapassam pessoas e se constituem no que é visível e invisível, ou em territórios subjetivos, minha intenção parece ter sido a de criar e sustentar um conflito onde existem relações de poder que deixam uns na posição de governante de vidas e outros supostamente assujeitados à essa posição. Nesse sentido, não posso deixar de sinalizar as considerações de Foucault acerca da hegemonia de uma hipótese repressiva no que tange a elaboração de um percurso histórico dos processos de subjetivação. O poder faz mais do que apenas reprimir: também cria, produz, direciona, conduz (FOUCAULT, 1979). A temática é outra, mas o mecanismo parece responder a lógica de uma mesma racionalidade, a de que os usuários são reprimidos e dominados pelo discurso médico. Nesse caso, aliás, fica mais sedutora a hipótese da repressão porque envolve a relação entre usuários e substâncias ilícitas, numa aliança médico-jurídica. Associo esse ponto de virada não só como um processo da formação em Psicologia, como também enquanto efeito da própria pesquisa sobre a disseminação da GAM. Ponto de virada este que avalio ser muito para além de uma capacidade de articulação mecânica e operacional dos conceitos, e dizer respeito também de um "dar-se conta", de um contato balizado por afetação.

Além do enfraquecimento de uma hegemonia da hipótese repressiva presente na relação médico-usuário, outra marca do processo de escrita foi o conflito gerado pela intenção de não elaborar uma teoria do sujeito. Deleuze é assertivo quando diz que "não há sujeito, mas uma produção de subjetividade: a subjetividade deve ser produzida quando chega o momento, justamente porque não há sujeito" (DELEUZE, 2006a, p. 141), presentificando o que seja da ordem da produção da subjetividade para além das linhas do saber e do poder. Portanto, não se trata de uma preocupação somente ontológica, mas principalmente do estudo das formas e modos como se produz a subjetividade. O que Foucault recusara seria a ideia de uma "verdade 
profunda" que serviria de marco à porta entreaberta da fenomenologia, que nos mostraria, enfim, onde estaria ontologicamente o sujeito. Para ele não há sujeito e sim subjetivação.

No âmbito da Psicologia, parece-me presente um constante esforço de descrição e domínio sobre os fenômenos. Nesse sentido, mesmo quando nos propomos a trazer considerações sobre os conceitos de discurso, por exemplo, as palavras surgiram quase como que num turbilhão de distanciamentos em que uma vontade oculta e maléfica da medicina era trazida a luz e denunciada em seu cerne embebido em violência. Falar disso seria, portanto, uma transgressão que promove prazer no acadêmico que deseja a diferenciação. $\mathrm{O}$ cômico é, contudo, que a denúncia seja a mais comum estratégia de trato com as problemáticas observadas no âmbito das políticas públicas.

Sigo sem saber muito bem o que está sendo referenciado pelos autores-amigos quando utilizam o termo cartografia. Contudo, não posso deixar de assinalar que como consideração pós-escrita houve uma desterritorialização: do acadêmico denunciante para algumas outras coisas possíveis. Dentre estas, talvez uma capaz de produzir novas máscaras, novas possibilidades de experiência com a Redução de Danos, com a Gestão Autônoma da Medicação, com a Psicologia e com a vida. Em outra oportunidade de cartografar os novos territórios que se efetuam com o término desse escrito, uma via possível seria conversar novamente com a médica e com o usuário, com a finalidade de enfraquecer pré-conceitos que paralisam funções, papéis e identidades, bem como promover a produção de outros encontros. Encontros estes onde a cogestão do fazer reflexivo que surge no "entre" RD e GAM se fazem possíveis. Mas por ora, cada um deambula em seu terreno, cada um abala o seu território. Alguns procuram, novamente, rochas firmes. Outros preferem a instabilidade de platôs que se afetam e que se abalam, produzindo um outro terreno, um outro território.

\title{
HARM REDUCTION AND AUTONOMOUS MEDICATION MANAGEMENT: CARTOGRAPHING THE EXPERIENCE OF AN ACADEMIC IN PSYCHOLOGY
}

\begin{abstract}
This paper aims to map the experience of a psychology student in a meeting about the theme of Harm Reduction (HR) and Autonomous Medication Management (GAM) in the city of Santa Maria/RS, where were participating patients, students, teachers and professionals in the field of mental health, alcohol and other drugs. The motivation for the research was the speech of a professional who said she preferred an interned and tied crack user rather than offering danger to society, because someone who consumes a benzodiazepine does not kill to sustain his addiction. One patient, in turn, responded by saying that she did not see it happening because the drug is available at any pharmacy. We look at the reverberations of this event, constituting our trajectory / method, inspired by cartography. We seek to build a historical narrative of drugs through the discursive field of HR and GAM, and map the production of subjectivity in the relationship with drugs in the movements of this meeting. Finally, we consider that there is Barbarói, Santa Cruz do Sul, n.54, p.<119-136>,jul./dez. 2019
\end{abstract}


something new between HR and GAM: the medicament use is becoming as important a problem as illicit drug use. Knowledge and practices are invested to invent and dispute ways of understanding and leading the ways of life that include psychoactive substances.

Keywords: harm reduction; autonomous medication management; cartography.

\section{REFERÊNCIAS}

BRASIL. Ministério da Saúde. Secretaria-Executiva. Secretaria de Atenção à Saúde. Legislação em saúde mental: 1990-2004. 5. ed. Brasília: Ministério da Saúde, 2004.

Lei $n^{\circ}$ 6.368, de 21 de outubro de 1976. Dispõe sobre medidas de prevenção e repressão ao tráfico ilícito e uso indevido de substâncias entorpecentes ou que determinem dependência física ou psíquica, e dá outras providências. Revogada pela Lei $n^{\circ} 11.343$. Diário Oficial [da] República Federativa do Brasil, Brasília, DF, 22 out. 1976. Disponível em: http://www.planalto.gov.br/ccivil_03/leis/L6368.html. Acesso em: 18 out. 2019.

Ministério da Saúde. Determina que as ações que visam à redução de danos sociais e à saúde, decorrentes do uso de produtos, substâncias ou drogas que causem dependência, sejam reguladas por esta Portaria. Portaria $\mathrm{n}^{\mathrm{o}} 1.028$ de 01 de julho de 2005. Diário Oficial [da] República Federativa do Brasil, Brasília, DF, 02 jul. 2005. Disponível em: http://bvsms.saude.gov.br/bvs/saudelegis/gm/2005/prt1028_01_07_2005.html. Acesso em: 18 out. 2019.

Ministério da Saúde. Institui a Rede de Atenção Psicossocial para pessoas com sofrimentos ou transtorno mental e com necessidades decorrentes do uso de crack, álcool e outras drogas, no âmbito do Sistema Único de Saúde. Portaria no 3.088 de 23 de dezembro de 2011. Diário Oficial [da] República Federativa do Brasil, Brasília, DF, 26 dez. 2011. Disponível em:http://bvsms.saude.gov.br/bvs/saudelegis/gm/2011/prt3088_23_12_2011_rep.html. Acesso em: 18 out. 2019.

BERNARDES, A. et al. Problema de Pesquisa como uma Estratégia Metodológica. In: FERREIRA, M.; MORAES, M. Políticas de Pesquisa em Psicologia Social. Rio de Janeiro: Nova Aliança, 2016.

CARNEIRO, H. O uso de drogas na sociedade. In F. de W. Oliveira \& H. Carneiro. Curso de Atualização em Álcool e Outras Drogas, da Coerção à Coesão. Álcool e sociedade (pp. 13 33). Florianópolis: Departamento de Saúde Pública/UFSC, 2014.

DELEUZE, G. Conversações. Rio de Janeiro: Editora 34, 1992. .; GUATTARI, F. O que é a Filosofia? Rio de Janeiro: Editora 34, 1992. Mil Platôs - Capitalismo e Esquizofrenia, v. 5. Rio de Janeiro: Editora 34, 1997.

DOMANICO, A. Craqueiros e Cracados: Bem Vindo ao Mundo dos Nóias. Estudo sobre a implementação de estratégias de redução de danos para usuários de crack nos cinco projetos piloto do Brasil. Tese de doutorado, Universidade Federal da Bahia, Salvador. 2006. 
DREYFUS, D.; RABINOW, P. Michel Foucault: uma trajetória filosófica. Rio de Janeiro: Forense Universitária, 1995.

FOUCAULT, M. Microfísica do poder. Rio de Janeiro: Edições Graal, 1979.

FONSECA, T. et al. O cotidiano frente à experiência liminar. Fractal: Revista de Psicologia, v. 30, n 2, p. 180-188, maio-ago. 2018. doi: https://doi.org/10.22409/1984-0292/v30i2/5548 FLACH, P. M. A implementação da política de atenção integral a usuários de álcool e outras drogas no Estado da Bahia. Dissertação de mestrado, Universidade Federal da Bahia, Salvador. (2010).

FURTADO, J.P.- Avaliação de programas e serviços de saúde. In: MINAYO, M. C. S.; CAMPOS, G. W. S.; AKERMAN, M.; DRUMOND, J. M.; CARVALHO, Y. (Org.). Tratado de saúde Coletiva. 1 ed. SP: Hucitec, v. 1. 2006. p. 669-714.

GUATTARI, F.; ROLNIK, S. Micropolítica: cartografias do desejo. Petrópolis: Vozes, 1996.

GUBA, E.G.; LINCOLN, Y.S. - Fourth Generation Evaluation. Sage Publications. Newbury Park. 1989. p. 294.

CAMPOS, R. T. O. et al. GUIA DA GESTÃO AUTÔNOMA DA MEDICAÇÃO - GAM. DSC/FCM/UNICAMP; ALFLORE; IPUB/UFRJ; DP/UFF; DPP/UFRGS, 2012.

HULL, S.A.; AQUINO, P.; COTTER, S. Explaining variation in antidepressant prescribing rates in east London: a cross sectional study. Fam. Pract., v.22, n.1. 2005. p.37-42.

MAKARY, A.; MICHAEL, D. Medical error - the third leading cause of death in the US BMJ 2016; 353:i2139.

MARAGNO, L. et al. Prevalence of common mental disorders in a population covered by the Family Health Program (QUALIS) in Sao Paulo, Brazil. Cad. Saúde Pública, v.22, n.8. 2006. p. 1639-48.

MACHADO, L. V.; BARINI, M. L. M. Políticas sobre drogas no brasil: a estratégia de Redução de Danos. Psicologia: ciência e profissão, 2013.

R.L. ET AL. The NIMH Epidemiologic Catchment Area Program: historical context, major 187 objectives, and study population characteristics. Arch Gen Psychiatry. 41 (10): 934-41. 1998.

PACHECO, M. E. A. G. Política de Redução de Danos a usuários de substâncias psicoativas: práticas terapêuticas no projeto consultório de rua em Fortaleza, Ceará. Dissertação de mestrado, Universidade Estadual do Ceará, Fortaleza. 2013.

PASSOS, E.; KASTRUP, V.; ESCÓSSIA, L. de (Org.). Pistas do método da cartografia. Porto Alegre: Editora Sulina, 2012. 
.; Souza, T. P. Redução de Danos e saúde pública: construções alternativas à política global de guerra às drogas. Psicologia Sociedade, 23 (1), 154 162. Recuperado de http://www.scielo.br/pdf/psoc/v23n1/a1 7v23n1.pdf. 2011.

ROBERTS, F. et al. Uso de psicotrópicos da Atenção Primária do Distrito Sudoeste de Campinas e sua relação com os arranjos da clínica ampliada: "uma pedra no sapato". 2009. Dissertação (Programa de pós-graduação em Saúde Coletiva - Mestrado) - Universidade Estadual de Campinas, Campinas.

TEDESCO S.; SOUZA T. Territórios da clínica: redução de danos e os novos percursos éticos para a clínica das drogas. In: CARVALHO, S.; BARROS, M.; FERIGATO, S. (Org.). Conexões: Saúde Coletiva e políticas da subjetividade. São Paulo: Aderaldo \& Rothschild, 2009. p. 141-56.

Agradecimentos e Agência(s) de fomento

Trabalho vinculado à bolsa CAPES e ao Programa de Cooperação Acadêmica (PROCAD), Edital nº71 /2013. Projeto de nº 88887.124178/2014-00 - Psicologia e políticas públicas: saúde e desenvolvimento em contextos de vulnerabilidade social. Processo de $\mathrm{n}^{\circ}$ 88887.166850/2018-00.

Data de recebimento: 09/08/2019

Data de aceite: $13 / 11 / 2019$

\section{Sobre os autores:}

Thales William Borges Lindenmeyer é acadêmico de Psicologia da UFSM. Endereço Eletrônico: thales.lindenmeyer@gmail.com

Maria Luiza Diello é Psicóloga, Mestre em Filosofia - UFSM/UNIJUI e Mestre em Psicologia - UFSM. Endereço Eletrônico: marialuizadiello@hotmail.com

Marcos Adegas de Azambuja é Doutor em Psicologia pela PUCRS e Professor Adjunto do Departamento de Psicologia e do Programa de Pós Graduação em Psicologia da UFSM Endereço Eletrônico: marcos.azambuja@ufsm.br

\footnotetext{
i "Programa de extensão: implementação e apoio aos grupos da Gestão Autônoma da Medicação da $4^{\mathrm{a}}$ coordenadoria regional do estado do Rio Grande do Sul" e "Ações de qualificação e fortalecimento da estratégia da Gestão Autônoma da Medicação (GAM) na região da 4 a coordenadoria regional de saúde, RS”.

ii Moradia destinada aos estudantes da UFSM em vulnerabilidade socioeconômica.

iii $\mathrm{O}$ caráter dos encontros inclui-se na perspectiva das abordagens avaliativas de quarta geração, tal como as descrevem autores como Guba \& Lincoln (1989) e Furtado (2006). Nesse tipo de abordagem, busca-se contemplar tanto as questões do avaliador-pesquisador quanto as dos grupos diretamente implicados no serviço. A pesquisaavaliativa propicia a inclusão de diferentes pontos de vista; viabilizar e ampliar a utilização dos resultados da avaliação; considerar o inevitável caráter político da pesquisa e; 'empoderar' os grupos envolvidos com os serviços, possibilitando que se apropriem dos conhecimentos gerados na realização do processo avaliativo.
} 